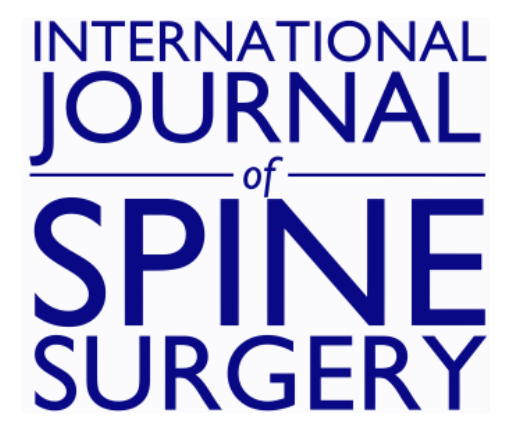

\title{
Relationship between psoas muscle dimensions and post operative thigh pain. A possible preoperative evaluation factor
}

Josip Buric

Int J Spine Surg 2015, 9 ()

doi: https://doi.org/10.14444/2027

http://ijssurgery.com/content/9/27

This information is current as of April 26, 2023.

Email Alerts Receive free email-alerts when new articles cite this article. Sign up at:

http://ijssurgery.com/alerts

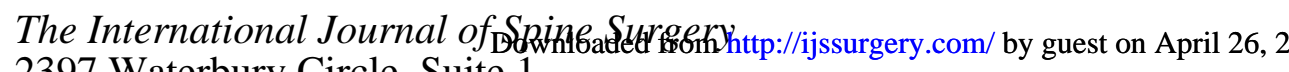
2397 Waterbury Circle, Suite 1,

Aurora, IL 60504, Phone: +1-630-375-1432

(C) 2015 ISASS. All Rights Reserved. 


\section{Relationship between psoas muscle dimensions and post operative thigh pain. A possible preoperative evaluation factor}

Josip Buric

Villa Torri Hospital, Bologna, Italy

\section{Abstract}

Introduction

Advanced intraoperative neuromonitoring (IONM) is used to attenuate postoperative complications and side effects of extreme lateral interbody fusion (XLIF). Specific factors relate to the presence of postoperative injury are not well understood. This study aims to identify intraoperative variables with correlations to new postoperative anterior thigh/groin sensory changes.

\section{Methods}

Twenty-nine patients with various degenerative lumbar conditions were treated with XLIF at a single institution. Mean age was 59 years, $69 \%$ were female, and $21 \%$ had undergone previous lumbar surgery. A total of 47 levels (mean 1.6, range 1-3) were treated with XLIF. Supplemental pedicle screw and rod fixation was used in 24 patients (83\%). Dynamically-evoked electromyography was used in all cases. Analysis of baseline demographic and treatment variables were performed at a per patient basis $(n=29)$, whereas analysis of intraoperative variables were performed at a per levels treated basis $(n=47)$.

Results

Within 24 hours postoperative, 10 (34\%) patients experienced anterior thigh/groin sensory changes (4 reported pain only, 5 reported pain plus other sensory changes, and 1 paresthesia without pain). Symptom resolution occurred at 1 month postoperative for 4 patients, at 3 months postoperative for 2 patients. At 3 months postoperative, 6 patients had complete symptom resolution, 3 patients had symptom improvements, and 1 patient had no change in perioperative symptoms. Psoas dimension in the lateral-latero direction were significantly smaller for patients with postoperative sensory changes $(\mathrm{p}=0.025)$, and similarly, patients with postoperative sensory changes had a significantly higher ratio of psoas muscle in the anterior-posterior to lateral-latero directions $(\mathrm{p}=0.026)$.

\section{Conclusions}

In addition to IONM, MRI evaluation of psoas shape, position, and dimension may be of help in preoperative planning of a safe XLIF access and eventually, predict those cases with higher risk of approach-related post-operative events.

KEYWORDS: INTRAOPERATIVE NEUROMONITORING, XLIF, PSOAS, EMG

VOLUME 9 ARTICLE 27 DOI: 10.14444/2027

\section{Introduction}

Extreme lateral interbody fusion (XLIF) has been reported in the literature for the treatment of a wide range of spinal pathologies intended to minimize the risks and morbidity associated with conventional posterior and anterior approaches to the spine. ${ }^{1-4}$ This retroperitoneal, $90^{\circ}$ lateral approach technique utilizes a transpsoas access to the disc space, and places the psoas muscle and nerves of the lumbar plexus at risk for injury. Advanced intraoperative neuromonitoring (IONM), including dynamicallyevoked electromyography (EMG) and free-run EMG, is used to attenuate approach related postoperative complications. ${ }^{5}$

However, even with advanced techniques for IONM, the close proximity of the surgical working space places at risk of injury the motor and sensory nerves of the lumbar plexus and surrounding anatomy, and occasionally results in new postoperative weakness of the hip flexors and/or sensory changes to the upper 
medial thigh/groin area.$^{6-8}$ Varying rates of sensory changes following XLIF have been reported in the literature, and there is not yet a consensus regarding factors associated with upper medial thigh pain.

Thus, the purpose of this study was to evaluate preand intra-operative variables significantly correlated with newly developed post-operative pain or motor or sensory events due to surgical positioning of the laterally-delivered interbody cage.

\section{Methods}

Intraoperative and postoperative clinical data were collected prospectively for 29 consecutive patients treated with XLIF at a single institution between 2012 and 2013. Mean age at time of surgery was 59 years (range 32 to 82 ) and 69\% were female. Six (21\%) patients had a history of previous lumbar surgery ( 2 fusion, 4 decompression). All patients were treated for one or more degenerative lumbar conditions, most commonly for degenerative disc disease (23, $79 \%)$, olisthesis $(8,28 \%)$, and/or stenosis $(6,21 \%)$. Complete cumulative indications for surgery are presented in Table 1. Preoperative symptoms included low back pain (LBP) in $90 \%$ of patients, bilateral or unilateral radiculopathy in $86 \%$, and other various symptoms (neurogenic claudication, motor deficits, palsy) in $28 \%$ of patients.

Preoperative magnetic resonance imaging (MRI) was obtained for all patients to evaluate psoas dimensions in both the antero-posterior (AP) and latero-lateral (LL) directions. IONM for all cases included dynamically-evoked electromyography (EMG). In this technique, as previously described ${ }^{1,9}$ three sequential dilators were placed at various depths of the psoas, rotated $360^{\circ}$, and direction of the lowest threshold (anterior, posterior, medial) was noted (EMG threshold, defined as the number of milliamperes required to depolarize a nerve, decreases with increased proximity to the nerve). Free-run (spontaneous) EMG readings throughout the duration of each case were also recorded.

Within 24 hours postoperative, patients were examined and asked to describe the presence of any new symptoms, such as pain or sensory disturbance in the region of the anterior abdominal wall, groin or front thigh or weakness of the hip and thigh. If positive, the patients were classified in surgical events (SE) group. Unless a new SE was noted, this examination concluded each patient's participation. Patients with SE were actively followed at additional intervals (1 week, 6 weeks, 3 months) until symptoms were resolved or deemed permanent.

Statistical analysis included ANOVA and Pearson's chi-squared/Fishers' Exact tests. Analysis of baseline demographic and treatment variables were performed at a per-patient basis $(\mathrm{n}=29)$, whereas analysis of intraoperative variables were performed at a per-levels treated basis $(n=47)$. Significance was accepted for $\mathrm{p}<0.05$.

\section{Results}

A total of 45 disc levels were treated (mean 1.6 per patient, range 1-3) with XLIF: 6 (13\%) at L2-3, 14 $(31 \%)$ at L3-4, and 25 (56\%) at L4-5. The XLIF portion of one case was aborted due to the inability to find a safe passage through the psoas based on unfavorable EMG readings, and the patient received only instrumented posterolateral fusion. However, as the

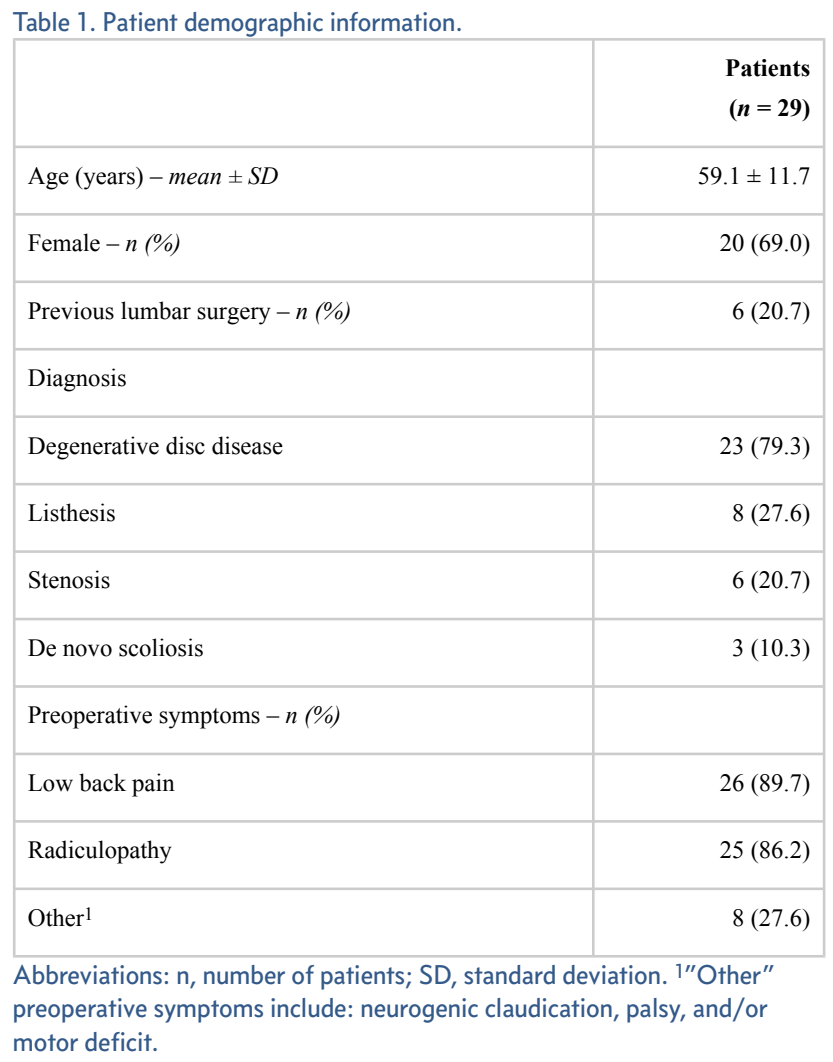


approach to the spine was performed and a postoperative $S E$ was noted, this patient was included for analysis in the current study. Supplemental pedicle screw and rod fixation was used in 24 (83\%) patients, an additional direct decompression was performed in 1 patient, and a Smith-Petersen osteotomy was performed in 1 patient. Blood loss for all patients was less than $50 \mathrm{cc}$, with the exception of one patient who experienced an intramuscular hematoma of the abdominal wall muscles requiring revision, resulting in $300 \mathrm{cc}$ blood loss.

\section{Nerve detection}

Alert-level EMG feedback (ie. nerves were identified within close proximity) during the approach to the spine was given in 16 of the 47 (34\%) levels treated. Close nerve proximity was detected in $0 \%$ of cases at $\mathrm{L} 2-3$, in $13 \%$ at $\mathrm{L} 3-4$, and in $56 \%$ at $\mathrm{L} 4-5$ ( $\mathrm{p}=0.003$ ). Direction of lowest threshold was noted as posterior in all 16 cases, with a mean threshold value of 9.7 $\mathrm{mA}$.

New postoperative surgical events (SE)

New postoperative anterior thigh/groin SE were present in 10 of 29 patients treated at 20 levels within 24 hours postoperative, 9 of which were approachrelated (31\%). In the remaining case, a deficit was noted on the contralateral side due to intraoperative malpositioning of the cage. Patient-level descriptions of SE and resolution are shown in Table 2. At 1 month postoperative, symptoms were still present in 5 (17\%) patients and by 3 months postoperative, symptoms were still present in 4 (14\%) patients. By one year postoperative, $3(10 \%)$ patients had persistent symptoms, though milder in severity and able to be controlled with adequate pharmacological pain therapy.

\section{Factors affecting new postoperative surgical events} (SE)

Age, gender, previous lumbar surgery, and preoperative symptoms were similar between patients with and without postoperative SE. On average, patients who experienced postoperative $S E$ were treated at more levels compared to those with no SE (2.0 v. 1.4, $\mathrm{p}=0.039$ ). Analysis on a levels-treated basis showed no significant differences in specific lumbar levels treated or retraction time between patients with and without postoperative SE (Table 2, Table 3). Also, no significant differences were found between cage sizes implanted in patients with and without postoperative SE (Table 2). Alert-level EMG feedback during the approach was also found to have no significant association with presence of postoperative SE $(\mathrm{p}=0.905)$. Psoas dimensions in the LL direction were significantly smaller for patients with postoperative $S E$ ( $p=0.025)$, and similarly, patients with postoperative $S E$ had a significantly higher ratio of psoas muscle AP:LL dimension ( $\mathrm{p}=0.026)$.

\section{Discussion}

XLIF has gained in popularity in the last decade as a

\begin{tabular}{|c|c|c|c|c|c|}
\hline $\begin{array}{l}\text { Patient } \\
\text { Number }\end{array}$ & $\begin{array}{r}\text { SE } \\
\text { Description }\end{array}$ & $\begin{array}{r}\text { Levels } \\
\text { treated } \\
\text { (IONM } \\
\text { registered) }\end{array}$ & $\begin{array}{l}\text { Cage } \\
\text { size / } \\
\text { level }\end{array}$ & $\begin{array}{r}\text { SE } \\
\text { Location }\end{array}$ & Resolution \\
\hline 2 & Pain & $\begin{array}{r}\text { L2-3.L3-4 } \\
\text { (L4-5) }\end{array}$ & $\begin{array}{l}10 \mathrm{x} \\
22 \mathrm{x} \\
50 \mathrm{~L}\end{array}$ & $\begin{array}{r}\text { Anterior } \\
\text { thigh }\end{array}$ & 3 months \\
\hline 3 & $\begin{array}{r}\text { Pain and } \\
\text { quad palsy }\end{array}$ & L3-4 (L4-5) & $\begin{array}{l}10 \mathrm{x} \\
22 \mathrm{x} \\
55 \mathrm{~L}\end{array}$ & $\begin{array}{r}\text { Contralateral } \\
\text { thigh }\end{array}$ & Improved \\
\hline 4 & Pain & L3-4 (L4-5) & $\begin{array}{r}8 \mathrm{x} \\
18 \mathrm{x} \\
55 \mathrm{~L}\end{array}$ & $\begin{array}{r}\text { Anterior } \\
\text { thigh }\end{array}$ & 3 months \\
\hline 7 & Pain & L4-5 & $\begin{array}{r}10 \mathrm{x} \\
22 \\
\times 50 \\
\mathrm{~L}\end{array}$ & $\begin{array}{r}\text { Anterior } \\
\text { thigh }\end{array}$ & 1 month \\
\hline 10 & Pain & $\begin{array}{r}\text { L2-3, L3-4 } \\
\text { (L4-5) }\end{array}$ & $\begin{array}{l}10 \mathrm{x} \\
22 \mathrm{x} \\
55 \mathrm{~L}\end{array}$ & $\begin{array}{r}\text { Anterior } \\
\text { thigh }\end{array}$ & 1 month \\
\hline 14 & $\begin{array}{r}\text { Pain and } \\
\text { tingling }\end{array}$ & L3-4, L4-5 & $\begin{array}{r}10 \mathrm{X} \\
18 \mathrm{X} \\
55 \mathrm{~L} \\
8 \mathrm{X} \\
18 \mathrm{X} \\
55\end{array}$ & $\begin{array}{r}\text { Anterior } \\
\text { thigh }\end{array}$ & 1 month \\
\hline 17 & $\begin{array}{r}\text { Pain and } \\
\text { burning }\end{array}$ & L4-5 & $\begin{array}{l}10 \mathrm{x} \\
18 \mathrm{x} \\
45 \mathrm{~L}\end{array}$ & $\begin{array}{r}\text { Anterior } \\
\text { thigh }\end{array}$ & Improved \\
\hline 25 & Paresthesia & L3-4 (L4-5) & $\begin{array}{l}10 \mathrm{x} \\
22 \mathrm{x} \\
55 \mathrm{~L}\end{array}$ & $\begin{array}{r}\text { Anterior } \\
\text { thigh }\end{array}$ & 1 month \\
\hline 26 & $\begin{array}{r}\text { Pain and } \\
\text { paresthesia }\end{array}$ & $\begin{array}{r}\text { (L2-3), L3-4, } \\
\text { L4-5 }\end{array}$ & $\begin{array}{r}8 \mathrm{x} \\
22 \mathrm{x} \\
50 \mathrm{~L}\end{array}$ & $\begin{array}{r}\text { Inguinal } \\
\text { area }\end{array}$ & Improved \\
\hline 27 & $\begin{array}{r}\text { Pain and } \\
\text { hyposthesia }\end{array}$ & (L4-5) & $\begin{array}{c}8 \mathrm{X} \\
22 \mathrm{X} \\
55 \mathrm{~L}\end{array}$ & & Improved \\
\hline
\end{tabular}


minimally invasive alternative for the treatment of a broad range of lumbar spinal pathologies. Previous literature has reported that in comparison to conventional, open approaches, XLIF results in less intraoperative blood loss, lower complication rates, shorter hospital stays, and faster return to normal activities. ${ }^{1,-4}$ Compared to anterior approaches for interbody fusion, the lateral approach reduces the risk of injury to the major vascular structures, and possibly, avoids retrograde ejaculation or vaginal dryness in males and females, respectively. ${ }^{10,11}$ The stand-alone lateral approach also avoids complications associated with posterior lumbar fusion approaches, such as posterior muscle denervation, nerve root injuries and dural leaks. ${ }^{12}$

As is the case with all surgical procedures, XLIF is not without potential adverse events. As the technique utilizes a $90^{\circ}$ lateral, trans-psoas approach to the spine, retraction of the psoas muscle posteriorly is required in order to establish and maintain a working corridor to the spine ${ }^{6-8}$ This can place significant pressure on the motor and sensory nerves of the lumbar plexus, potentially leading to new postoperative neurological deficits. New upper medial thigh sensory deficits following XLIF in most cases are transient and resolve within the short-term postoperative period. ${ }^{2}$ The use of advanced IONM allows for the establishment of a safe working corridor by providing real-time, dynamic information on both the position and distance of motor nerves with respect to the instrument. ${ }^{9}$ However, due to the close anatomic proximity of the surgical working space to the ilioinguinal, iliohypogastric, and lateral femoral cutaneous nerves, risk of postoperative neurological deficit can

\begin{tabular}{|c|c|c|c|}
\hline & $\begin{array}{l}\text { No SE } \\
(n=27)\end{array}$ & $\begin{array}{r}\text { SE } \\
(n=20)\end{array}$ & p-value \\
\hline Retraction time (min) - mean $\pm S D$ & $31.5 \pm 2.2$ & $27.4 \pm 2.5$ & 0.217 \\
\hline Alert-level EMG response $-n(\%)$ & $13(41.9)$ & $7(43.8)$ & 0.905 \\
\hline \multicolumn{4}{|l|}{ Psoas dimensions - mean $\pm S D$} \\
\hline Anteroposterior & $38.1 \pm 2.0$ & $37.3 \pm 2.4$ & 0.814 \\
\hline Lateral & $31.9 \pm 1.8$ & $25.6 \pm 2.1$ & $0.025 *$ \\
\hline Ratio AP:Lateral & $1.3 \pm 0.1$ & $1.7 \pm 0.2$ & $0.026 *$ \\
\hline
\end{tabular}

only be mitigated but not eliminated with IONM. ${ }^{13}$

Previous studies have reported varying rates of postoperative neurologic events (motor or sensory) between 0.6 to $33.6 \%$ following XLIF., ${ }^{2,91,14}$ Tohmeh et al. reported new upper medial thigh sensory loss in $18 \%$ of patients and hip flexion weakness in $28 \%$ of patients. ${ }^{9}$ Most of these cases of postoperative events have been described as transient, due to trauma to the psoas during the approach as opposed to injury to the nerve roots. Some authors regard them more as a side effect of the lateral approach rather than a complication. The majority of these injuries have been reported to resolve without additional intervention, usually after 3 months postoperative, and a drastically lower number of these cases have been reported in the literature to be permanent. In a large series of 600 patients by Rodgers et al, the incidence of permanent neurologic injury was $0.7 \%$, while Pumberger et al. found $1.6 \%$ of patients with sensory deficits after 1 year postoperative. ${ }^{13} \mathrm{We}$ found it difficult, if not impossible, to establish if these new events were due to a nerve lesion or merely due to surgical trauma of the psoas muscle. This was specifically true for short-term weakness events and pain while long-term pain and sensory loss or otherwise disturbances could more easily be attributed to a nerve lesion. In the current study, 9 (31\%) patients experienced new approach-related groin and/or thigh event, characterized as pain, sensory reduction or loss and muscle weakness in 9 of the 10 patients. The symptoms were transient and resolved within 3 months for 6 of the 10 patients, while persisting at 1 year for 3 patients $(10 \%)$.

Specific factors related to the presence of postoperative SE following XLIF are not well understood. It has been previously reported that there is an increased risk of injury when treatment was inclusive of the L4-5 level due to a more anteriorly positioned lumbar plexus in the psoas muscle however, other reports have been conflicting. ${ }^{2,13,15}$ In the current study, while alert-level EMG feedback was given significantly more frequently at L4-5 compared with other levels, there were no significant differences in postoperative incidence of SE probably due to a relatively small group numbers that may not have adequately powered this study to detect the difference. Number

Downloaded from http://ijssurgery.com/ by guest on April 26, 2023 
of levels treated was significantly higher in the current study among patients with postoperative SE compared to those without, which corroborates with previously published reports in the literature.

The most significant finding of this study regarded the correlation of new post-op SE with psoas dimensions and shape. Specifically, patients with postoperative $S E$ had a mean psoas latero-lateral measure on preoperative axial MRI images, of $25.6 \mathrm{~mm}$, which was significantly less than the average measure of $31.9 \mathrm{~mm}$ for patients with no postoperative $\mathrm{SE}$ $(\mathrm{p}=0.025)$. As psoas measures in the AP direction were statistically similar between patients with and without postoperative $\mathrm{SE}(37.3 \mathrm{~mm}$ v. $38.1 \mathrm{~mm}$ ), patients with a postoperative $\mathrm{SE}$ also had a higher AP:LL psoas dimension ratio $(\mathrm{p}=0.026)$, reflecting a more anteriorly elongated psoas, as seen on axial MRI images. This association between psoas morphology and neural anatomy has also been previously described by Smith et al. ${ }^{16}$ In their study of feasibility of XLIF in treating transitional L5-6 levels, they found that the ability to establish a safe working corridor to the spine was limited in levels where surrounding psoas muscle was in a laterally detached, "teardrop shape" as evaluated on preoperative axial MRI. To our knowledge, this is the first report that provides quantitative data on the relationship between psoas morphology and risk of postoperative SE in non-transitional lumbar levels (L2-3, L3-4 and L4-5).

Finally, it is important to note that postoperative motor and sensory deficits are not exclusive to the XLIF procedure, but has also been extensively reported in the literature for other approaches, both open and minimally invasive (MI). In particular, permanent neurological deficits have been reported to be as high as $6.1 \%$ for posterior lumbar interbody fusion (PLIF) ${ }_{17}^{17} 4.1 \%$ for transforaminal lumbar interbody fusion (TLIF), ${ }^{11} 3.6 \%$ of posterior instrumented fusion (PLF), ${ }^{18}$ and $6.5 \%$ for endoscopic anterior lumbar interbody fusion (ALIF), ${ }^{19}$ and $1.5 \%$ for open ALIF. $^{20}$

\section{Conclusions}

Real-time, dynamic IONM during XLIF helps to minimize rates of new postoperative surgical events. Postoperative surgical events were found to occur more frequently in patients treated at multiple levels as well as in the patients with a higher anteriorposterior to latero-lateral psoas dimension ratio. In addition to IONM, MRI evaluation of psoas shape, position, and dimension may be of help in preoperative planning of a safe XLIF access and eventually, predict those cases with higher risk of approachrelated post-operative events.

\section{References}

1. Ozgur BM, Aryan HE, Pimenta L, Taylor WR. Extreme Lateral Interbody Fusion (XLIF): a novel surgical technique for anterior lumbar interbody fusion. Spine J 2006;6:435-43.

2. Rodgers WB, Cox CS, Gerber EJ. Early complications of extreme lateral interbody fusion in the obese. J Spinal Disord Tech 2010;23:393-7.

3. Lucio JC, Vanconia RB, Deluzio KJ, Lehmen JA, Rodgers JA, Rodgers W. Economics of less invasive spinal surgery: an analysis of hospital cost differences between open and minimally invasive instrumented spinal fusion procedures during the perioperative period. Risk Manag Healthc Policy 2012;5:65-74.

4. Smith WD, Christian G, Serrano S, Malone KT. A comparison of perioperative charges and outcome between open and mini-open approaches for anterior lumbar discectomy and fusion. J Clin Neurosci 2012;19:673-80.

5. Berjano $P$, Lamartina C. Minimally invasive lateral transpsoas approach with advanced neurophysiologic monitoring for lumbar interbody fusion. Eur Spine J 2011;20:1584-6.

6. Benglis DM, Vanni S, Levi AD. An anatomical study of the lumbosacral plexus as related to the minimally invasive transpsoas approach to the lumbar spine. J Neurosurg Spine 2009;10:139-44.

7. Moro T, Kikuchi S, Konno S, Yaginuma H. An anatomic study of the lumbar plexus with respect to retroperitoneal endoscopic surgery. Spine (Phila $\mathrm{Pa}$ 1976 ) 2003;28:423-8.

8. Park DK, Lee MJ, Lin EL, Singh K, An HS, Phillips FM. The relationship of intrapsoas nerves during a transpsoas approach to the lumbar spine: anatomic study. J Spinal Disord Tech 2010;23:223-8. 
9. Tohmeh AG, Rodgers WB, Peterson MD. Dynamically evoked, discrete-threshold electromyography in the extreme lateral interbody fusion approach. J Neurosurg Spine 2011;14:31-7.

10. Rajaraman V, Vingan R, Roth P, Heary RF, Conklin L, Jacobs GB. Visceral and vascular complications resulting from anterior lumbar interbody fusion. J Neurosurg 1999;91:60-4.

11. Villavicencio AT, Burneikiene S, Bulsara KR, Thramann JJ. Perioperative complications in transforaminal lumbar interbody fusion versus anteriorposterior reconstruction for lumbar disc degeneration and instability. J Spinal Disord Tech 2006;19:92-7.

12. Rodgers WB, Gerber EJ, Patterson J. Intraoperative and early postoperative complications in extreme lateral interbody fusion: an analysis of 600 cases.

Spine (Phila Pa 1976 ) 2011;36:26-32.

13. Pumberger $M$, Hughes AP, Huang RR, Sama AA, Cammisa FP, Girardi FP. Neurologic deficit following lateral lumbar interbody fusion. Eur Spine J 2012;21:1192-9.

14. Tormenti MJ, Maserati MB, Bonfield CM, Okonkwo DO, Kanter AS. Complications and radiographic correction in adult scoliosis following combined transpsoas extreme lateral interbody fusion and posterior pedicle screw instrumentation. Neurosurg Focus 2010;28:E7.

15. Kepler CK, Bogner EA, Herzog RJ, Huang RC. Anatomy of the psoas muscle and lumbar plexus with respect to the surgical approach for lateral transpsoas interbody fusion. Eur Spine J 2011;20:550-6. 16. Smith WD, Youssef JA, Christian G, Serrano S, Hyde JA. Lumbarized sacrum as a relative contraindication for lateral transpsoas interbody fusion at L5-6. J Spinal Disord Tech 2012;25:285-91.

17. Barnes B, Rodts GE, Jr., Haid RW, Jr., Subach BR, McLaughlin MR. Allograft implants for posterior lumbar interbody fusion: results comparing cylindrical dowels and impacted wedges. Neurosurgery 2002;51:1191-8.

18. Cho KJ, Suk SI, Park SR, et al. Complications in posterior fusion and instrumentation for degenerative lumbar scoliosis. Spine (Phila Pa 1976) 2007; 32:2232-7.

19. Bergey DL, Villavicencio AT, Goldstein T, Regan JJ. Endoscopic lateral transpsoas approach to the lumbar spine. Spine (Phila Pa 1976 ) 2004;29:1681-8. 20. Sasso RC, Best NM, Mummaneni PV, Reilly TM, Hussain SM. Analysis of operative complications in a series of 471 anterior lumbar interbody fusion procedures. Spine (Phila Pa 1976 )

2005;30:670-4.

\section{Disclosures}

The author acts as a proctor for NuVasive.

\section{Corresponding Author}

Josip Buric, Villa Torri Hospital, Viale Quirico Filopanti, 1240126 Bologna, Italy. joburic77@gmail.com.

Published 7 July 2015.

This manuscript is generously published free of charge by ISASS, the International Society for the Advancement of Spine Surgery. Copyright @ 2015 ISASS. To see more or order reprints or permissions, see http://ijssurgery.com. 